\title{
MicroRNA-381 regulates the growth of gastric cancer cell by targeting TWIST1
}

\author{
YONGLING YIN $^{1}$, XIAOYUN LI ${ }^{2}$, ZONGQUAN GUO ${ }^{3}$ and FUXIANG ZHOU ${ }^{1}$ \\ ${ }^{1}$ Department of Radiation and Medical Oncology, Zhongnan Hospital of Wuhan University, \\ Wuhan, Hubei 430071; ${ }^{2}$ Department of Internal Medicine-Oncology; ${ }^{3}$ Digestive Department, \\ Affiliated People's Hospital of Inner Mongolia Medical University, Hohhot, Inner Mongolia 010020, P.R. China
}

Received June 21, 2018; Accepted January 29, 2019

DOI: $10.3892 / \mathrm{mmr} .2019 .10651$

\begin{abstract}
Gastric cancer (GC) has one of the highest mortality rates among all types of cancer in the world. At present, an efficient treatment for GC remains elusive. Studies have demonstrated that microRNAs (miRs) are abnormally expressed in cancer, and that these serve important roles in the development and metastasis of various human tumors, including GC. It has been suggested that regulation of miRs may bring about new developments in GC therapy. miR-381 has been reported to be downregulated in human cancer, and it regulates cancer cell growth in numerous types of cancer. The present study reports that miR-381 was downregulated in GC cells, and upregulation of miR-381 may inhibit GC cell growth, which may be attributed to the inhibition of cell proliferation and the promotion of apoptosis. Furthermore, Twist-related protein 1 (TWIST1) was predicted and confirmed to be a direct target of miR-381 by dual-luciferase assay in GC. Upregulation of miR-381 caused a decrease in the expression of TWIST1 at the mRNA and protein levels in GC cells. Taken together, the present study demonstrated that miR-381 is downregulated in GC cells, and that miR-381 may inhibit GC cell growth. Therefore, miR-381 may serve as a novel target for the clinical treatment of GC in the future.
\end{abstract}

\section{Introduction}

Gastric cancer (GC) is one of the most common types of gastrointestinal cancer, being the second leading cause of tumor-associated mortality in the world (1-4). It is reported that the 5-year survival rate of patients with GC is $20 \%$ (5). The high mortality rate is primarily due to late diagnosis and local and systemic metastasis (6-9). Surgery is the principal

Correspondence to: Dr Fuxiang Zhou, Department of Radiation and Medical Oncology, Zhongnan Hospital of Wuhan University, 169 East Lake Road, Wuchang, Wuhan, Hubei 430071, P.R. China E-mail: fuxiangzhou6@outlook.com

Key words: microRNA-381, gastric cancer cell, proliferation, apoptosis, Twist-related protein 1 treatment, and metastases are observed in the majority of patients with advanced GC. Advances in diagnostic and therapeutic approaches have led to improved expectations for the long-term survival of patients with early GC. However, the prognosis for advanced GC with extensive invasion and metastasis remains poor (10). Therefore, understanding the potential molecular underpinnings of the GC metastatic process is critical for the development of novel treatments.

MicroRNAs (miRs) are endogenous non-coding RNAs. They are formed of 18-25 nucleotides and regulate gene expression by binding to the untranslated region (UTR) of mRNAs $(11,12)$. miRs serve important and diverse roles in numerous biological processes by controlling the translation of mRNA, including cell growth and metabolism (13-15). Furthermore, miRs serve important roles in multiple aspects of tumor development, including cell proliferation, apoptosis, invasion and migration (16). Increasing evidence has indicated that miR-381 is abnormally expressed in various types of tumors, including lung cancer, prostate cancer, cervical carcinoma and GC (17-20), and that miR-381 may regulate various biological aspects of tumorigenesis (21). Previous studies have reported miR-381 is upregulated in glioma and acts as an oncogene (18); however, it is downregulated in renal cancer cells, lung adenocarcinoma and glioblastoma, and exhibits the characteristics of a tumor suppressor in these types of cancer $(1,17,19)$. Liao et al (22) reported that Twist-related protein 1 (TWIST1) was a direct target of miR-381, and that miR-381 regulated the growth and migration of pituitary adenoma cells by targeting TWIST. However, the biological role of miR-381 in GC remains poorly investigated. In the present study, the biological effect of miR-381 and the association between miR-381 and TWIST1 in GC cells was investigated.

\section{Materials and methods}

Cell culture. The human gastric adenoma cell line BGC-823 (cat. no. TCHu 11) and human gastric adenoma cell line SGC-7901 (cat. no. TCHu 46) were purchased from the Type Culture Collection of the Chinese Academy of Sciences (Shanghai, China). The human gastric epithelial cell line MKN-28 (cat. no. CL-0291) and the human gastric epithelial mucosa cells (GES; cat. no. CL-0563) were purchased from 
Procell Life Science \& Technology Co., Ltd. (Wuhan, China). The cells were cultured in RPMI 1640 medium (Invitrogen; Thermo Fisher Scientific, Inc., Waltham, MA, USA) supplemented with 1:10 fetal bovine serum (FBS; Invitrogen; Thermo Fisher Scientific, Inc.), penicillin (1:100; Invitrogen; Thermo Fisher Scientific, Inc.) and streptomycin (1:100; Invitrogen; Thermo Fisher Scientific, Inc.) in a humidified atmosphere containing $5 \% \mathrm{CO}_{2}$ at $37^{\circ} \mathrm{C}$.

Transfection assay. The GC cell line SGC-7901 was cultured in medium without antibiotics for $24 \mathrm{~h}$. miR-381 mimic (cat. no. 4464066) or miR-381 negative control (NC; cat. no. 4464059) (Ambion; Thermo Fisher Scientific, Inc.) were transfected into the cultured SGC-7901 cells (5,000 cells/well in a 96-well plate) at a final concentration of $10 \mathrm{nM}$ using the Lipofectamine ${ }^{\circledR} 3000$ reagent (Invitrogen; Thermo Fisher Scientific, Inc.), according to the manufacturer's instructions. The miR-381 NC was used as the negative control. Protein and total RNA were extracted from the transfected cells $72 \mathrm{~h}$ after transfection. TWIST1 small interfering RNA (siRNA; cat. no. sc-38604) was purchased from Santa Cruz Biotechnology, Inc. (Dallas, TX, USA). TWIST1 siRNA transfection was performed using the Lipofectamine ${ }^{\circledR} 3000$ reagent according to the manufacturer's instructions. Cells were harvested for further study $24 \mathrm{~h}$ post-transfection.

Reverse transcription-quantitative polymerase chain reaction $(R T-q P C R)$. Total miRs and mRNAs were extracted from transfected and mock GC cells using TRIzol ${ }^{\circledR}$ (Invitrogen; Thermo Fisher Scientific, Inc.). miRs were converted to cDNAs via PrimeScript miRNA cDNA Synthesis kit (cat. no. D350A; Takara Bio, Inc., Otsu, Japan) and mRNAs were converted to cDNAs by using the PrimeScript RT Master Mix kit (cat. no. DRR036A; Takara Bio, Inc.). miRNA RT was conducted under the following conditions: $42^{\circ} \mathrm{C}$ for $60 \mathrm{~min}$ and $85^{\circ} \mathrm{C}$ for $15 \mathrm{~min}$. mRNA RT was conducted under the following conditions: $37^{\circ} \mathrm{C}$ for $15 \mathrm{~min}$ and $85^{\circ} \mathrm{C}$ for $1 \mathrm{~min}$. miR-381 quantification was performed via TaqMan Universal PCR Master Mix with a miRNA-specific TaqMan minor groove binder probe (cat. no. 4426961; Invitrogen; Thermo Fisher Scientific, Inc.), according to the manufacturer's instructions. RNA U6 was used as internal control for miR-381 quantification. The sequences for U6 were: F: 5'-GTGCTCGCTTCGGCAGCACATATAC-3'; R: 5'-AAAAATATGGAACGCTCACGAATTTG-3'. The sequences for GAPDH (cat. no. qHsaCEP0041396; Bio-Rad Laboratories, Inc.) and miR-381 (cat. no. 4426961; Invitrogen; Thermo Fisher Scientific, Inc.) were proprietary. The qPCR for TWIST1 was performed using PrimePCR ${ }^{\mathrm{TM}}$ SYBR $^{\circledR}$ Green Assay (cat. no. qHsaCED0043959; Bio-Rad Laboratories, Inc., Hercules, CA, USA). GAPDH was the internal control gene for TWIST1 quantification. qPCR was conducted under the following conditions: $95^{\circ} \mathrm{C}$ for $10 \mathrm{~min}$, followed by 40 cycles at $95^{\circ} \mathrm{C}$ for $10 \mathrm{sec}, 57^{\circ} \mathrm{C}$ for $20 \mathrm{sec}$ and $72^{\circ} \mathrm{C}$ for $10 \mathrm{sec}$. Relative quantifications of miRs and mRNAs were calculated using the $2^{-\Delta \Delta \mathrm{Cq}}$ method as previously described (23).

miRNA target predictions. To further investigate the potential target of miR-318, potential genes were predicted using TargetScan 7.2 (www.targetscan.org) and miRBase (www. mirbase.org).
Dual luciferase assay. The wild-type (wt; GUUUUGUAA AUAUCUUUGUAUA) or mutant (mut; GUUUUGUAAAUA UCUCCACGCA) TWIST1 genes were cloned downstream of the luciferase gene in the pLUC Luciferase vector to construct the TWIST1 luciferase reporter vector (Qcbio S\&T Co., Ltd.). miR-381 mimic or miR-381 NC were co-transfected with the TWIST1 luciferase reporter vector into the GC cell line SGC-7901 (10,000 cells/well in a 48-well plate) using Lipofectamine ${ }^{\circledR} 3000$ (Invitrogen; Thermo Fisher Scientific, Inc.), according to the manufacturer's instructions. The transfected cells were cultured at $37^{\circ} \mathrm{C}$ for $48 \mathrm{~h}$, harvested and lysed for the measurement of luciferase activity according to the manufacturer's instructions (Dual-Luciferase ${ }^{\circledR}$ Reporter Assay system; Promega Corporation). The relative luciferase activity was normalized to Renilla luciferase activity.

Cell viability and colony formation assays. An MTT assay was used to evaluate the effect of miR-381 on GC cell viability. GC cells transfected with miR-381 mimic or miR-381 NC were cultured in 96-well plates (5,000 cells/well). Cell viability was measured by MTT assay every $24 \mathrm{~h}$ according to the manufacturer's instructions. Following incubation with MTT reagent, formazan crystals were dissolved in DMSO and optical density was measured at $490 \mathrm{~nm}$. For the colony formation assay, GC cells transfected with miR-381 mimic or miR-381 $\mathrm{NC}$ were cultured in 6-well plates for 2 weeks (500 cells/well), fixed with $100 \%$ methanol at room temperature (RTemp) for $15 \mathrm{~min}$, and stained with $0.5 \%$ crystal violet at $4^{\circ} \mathrm{C}$ for $30 \mathrm{~min}$ to count the number of colonies using a light microscope (magnification, $\mathrm{x} 4$ ).

Transwell cell migration and invasion assays. Cell invasion and migration were assessed using a Transwell chamber coated with or without Matrigel (EMD Millipore), respectively, according to the manufacturer's protocol. miR-381 mimic or miR-381 NC transfected GC cells $(100,000)$ were cultured in serum free medium and seeded in the upper chamber (pore size, $8 \mu \mathrm{m}$ ). The lower chamber contained the chemoattractant medium with $10 \%$ FBS. After $48 \mathrm{~h}$, the cultured cells in the upper chamber were removed using a cotton swab, while the cells which had migrated to the reverse face were fixed with 4\% methanol for $20 \mathrm{~min}$ at RTemp, and stained with giemsa for $15 \mathrm{~min}$ at RTemp to count the cell numbers using a light microscope (magnification, x200).

Cell apoptosis assay. miR-381 mimic or miR-381 NC transfected GC cells were cultured for 2 days in RPMI1640 medium. Harvested cells were stained with fluorescein isothiocyanate-Annexin V and propidium iodide (PI; Beyotime Institute of Biotechnology). A flow cytometry (FCM) assay was performed to evaluate cell apoptosis (BD FACSCalibur; BD Biosciences), and the data were analyzed with CellQuest Pro 7.5.3 software (BD Biosciences).

Western blotting. miR-381 mimic or miR-381 NC transfected GC cells were cultured for 2 days in 6-well plates. Cells were harvested and protein was extracted using a radioimmunoprecipitation assay buffer containing protease inhibitors (Beyotime Institute of Biotechnology). Protein concentration was measured using the bicinchoninic acid assay. The 
extracted proteins $(50 \mu \mathrm{g})$ were separated by $10 \%$ SDS-PAGE and transferred onto a polyvinylidene difluoride (PVDF) membrane. The PVDF membrane was blocked with 5\% milk in PBS-0.05\% Tween 20 (PBST) for $2 \mathrm{~h}$ at RTemp, and incubated with the following primary antibodies $(1: 2,000)$ : TWIST1, (cat. no. 46702) and GAPDH (cat. no. 5174; both Cell Signaling Technology, Inc.) for $2 \mathrm{~h}$ at RTemp. Following three washes with PBST, the PVDF membrane was incubated with anti-rabbit secondary antibodies (1:2,000; cat. no. 7074; Cell Signaling Technology, Inc.) for $1 \mathrm{~h}$ at RTemp. Following three washes with PBST, the target proteins were detected with an enhanced chemiluminescent kit (cat. no. P0018; Beyotime Institute of Biotechnology) and exposed on x-ray film.

Statistical analysis. Each experiment was repeated at least three times. SPSS 16.0 (SPSS, Inc., Chicago, IL, USA) was used to perform one-way analysis of variance and Tukey's HSD tests (post-hoc test) to identify statistical differences. The data are expressed as the mean \pm standard deviation. $\mathrm{P}<0.05$ was considered to indicate a statistically significant difference.

\section{Results}

miR-381 is downregulated in GC cells. In order to determine the expression of miR-381 in human GC cells, total RNA was extracted from cultured cell lines, and the expression levels of miR-381 were measured via RT-qPCR. The relative expression of miR-381 was normalized to the endogenous U6 RNA expression. The expression of miR-381 (Fig. 1) was significantly decreased in GC cell lines compared with the immortalized human gastric epithelial GES cells $(\mathrm{P}<0.05)$. Notably, in SGC-7901 cells, the relative expression of miR-381 was $\sim 0.24$ relative to GES cells; therefore, SGC-7901 cells were used in the subsequent experiments.

TWIST1 is a direct target of miR-381 in GC cells. To investigate the biological function of miR-381 in GC cells, the direct target gene of miR-381 was identified using the miRBase database. The search results indicated that TWIST1 was a potential target of miR-381 (Fig. 2A). Previous studies reported that TWIST1 is upregulated in GC, and that TWIST1 promotes GC cell proliferation $(24,25)$, therefore miR-381 was hypothesized to regulate GC cells via TWIST1. To confirm whether TWIST1 is a direct target gene of miR-381, a dual luciferase assay was performed in SGC-7901 cells. Luciferase reporter plasmids with either the wt or mut targeting sequence of TWIST1 mRNA were created (Fig. 2A). These were co-transfected with miR-381 mimic or miR-381 NC into SGC-7901 cells, cultured for $48 \mathrm{~h}$, and the luciferase activity was measured. As indicated in Fig. 2B, miR-381 significantly decreased the luciferase activity of the wt TWIST1 UTR reporter $(\mathrm{P}<0.05)$, while the transfection with the mut UTR of TWIST1 did not. These results demonstrated that TWIST1 was a direct target gene of miR-381.

$m i R-381$ inhibits $G C$ cell viability. To investigate the effect of miR-381 on GC SGC-7901 cell viability, an MTT assay was performed. To evaluate the effect of miR-381 expression, the mimic transfection assay was used. Transfection of miR-381 mimic significantly increased the expression of

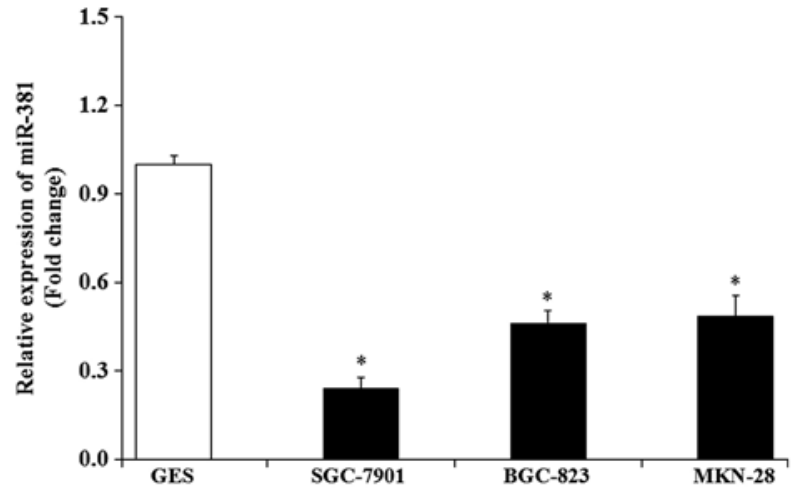

Figure 1. Relative expression of miR-381 in gastric cancer cell lines. The expression of miR-381 was measured using a reverse transcription-quantitative polymerase chain reaction assay. The relative gene expression was normalized to U6, and the data are presented as the mean \pm standard deviation. ${ }^{*} \mathrm{P}<0.05$ vs. GES. miR, microRNA.
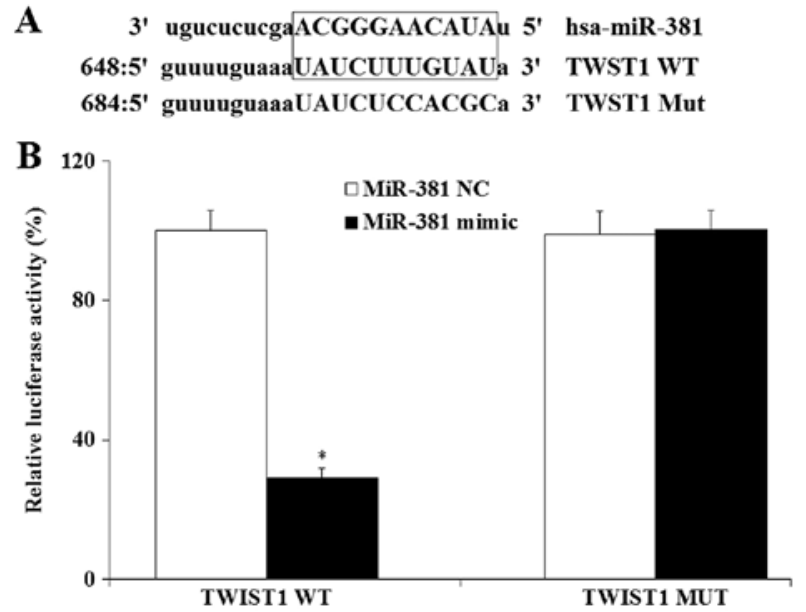

Figure 2. miR-381 directly targets TWIST1 in gastric cancer cells (A) Sequences of the 3'untranslated region of wild-type and mutant forms of TWIST1 mRNA and miR-381 sequence. (B) Luciferase activity in the SGC-7901 cells. Data are presented as the mean \pm standard deviation. ${ }^{*} \mathrm{P}<0.05$ vs. respective miR-381 NC. miR, microRNA; TWIST1, Twist-related protein 1 ; NC, negative control.

miR-381 compared with the miR-381 NC and mock groups (Fig. 3A). The MTT results indicated that miR-381 significantly decreased the viability of SGC-7901 cells compared with mock and miR-381 NC cells $(\mathrm{P}<0.05)$, while there was no significant difference between miR-381 NC and mock group (Fig. 3B). Further to these results, colony formation assays demonstrated that miR-381 expression resulted in fewer SGC-7901 cell colonies compared with mock and miR-381 NC $(\mathrm{P}<0.05$; Fig. $3 \mathrm{C})$. No significant differences in the number of colonies between the miR-381 NC and mock group were observed (Fig. 3C). These results revealed that miR-381 may serve an important role in GC cell viability, and that induction of miR-381 expression may inhibit GC cell proliferation.

miR-381 inhibits GC cell invasion and migration. The effect of miR-381 on GC cell invasion and migration was also verified to further characterize miR-381 in GC. The results indicated that upregulation of miR-381 affected cell migration and invasion in a Transwell chamber (Fig. 4A): Upregulation of miR-381 

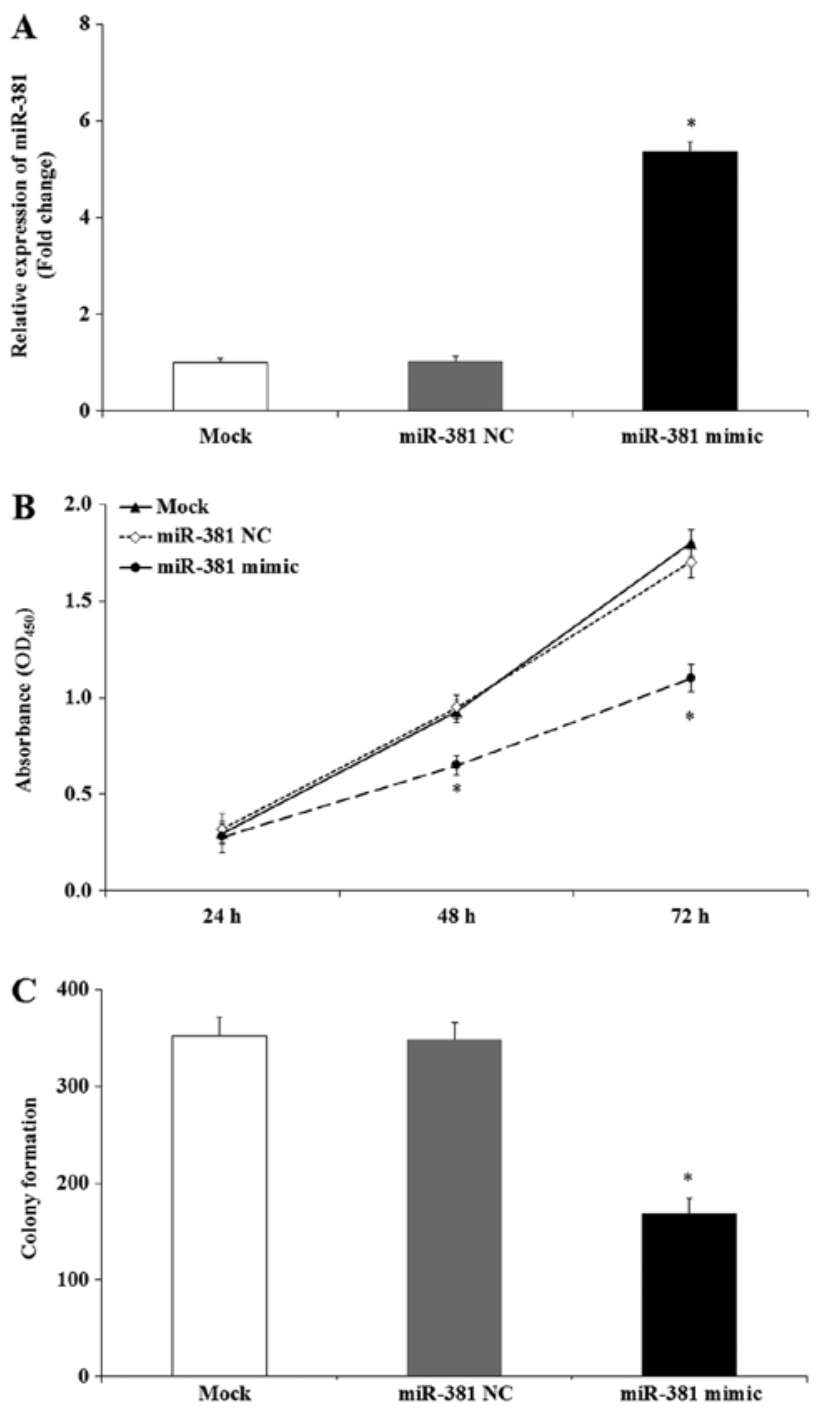

Figure 3. miR-381 inhibits gastric cancer SGC-7901 cell growth and proliferation. (A) Expression of miR-381 in mock and transfected SGC-7901 cells. (B) miR-381 significantly decreased SGC-7901 cell viability, as assessed via MTT. (C) miR-381 overexpression significantly reduced the colony forming ability of SGC-7901 cells. The data are presented as the mean \pm standard deviation. ${ }^{*} \mathrm{P}<0.05$ vs. respective Mock cells. miR, microRNA; NC, negative control.

inhibited the migration and invasion capacity of SGC-7901 cells. The cells that successfully migrated in the miR-381 upregulation group corresponded to $\sim 1 / 3$ of the number of cells in the miR-381 NC group (Fig. 4B). Therefore, the data suggested that miR-381 may regulate GC growth through the inhibition of cell proliferation, migration and invasion.

miR-381 induces GC cell apoptosis. TWIST1 was verified to be a direct target of miR-381, and a previous study indicated that TWIST1 regulation was associated with cell apoptosis (26). Therefore the effect of miR-381 GC cell apoptosis was evaluated. SGC-7901 cells transfected with miR-381 mimic or miR-381 NC were cultured for $48 \mathrm{~h}$, harvested and stained with PI and Annexin V for an FCM assay. The results indicated that the percentage of apoptotic cells in the miR-381 mimic group was increased compared with the miR-381 NC group $(\mathrm{P}<0.05$; Fig. 5), which suggests
$\mathbf{A}$
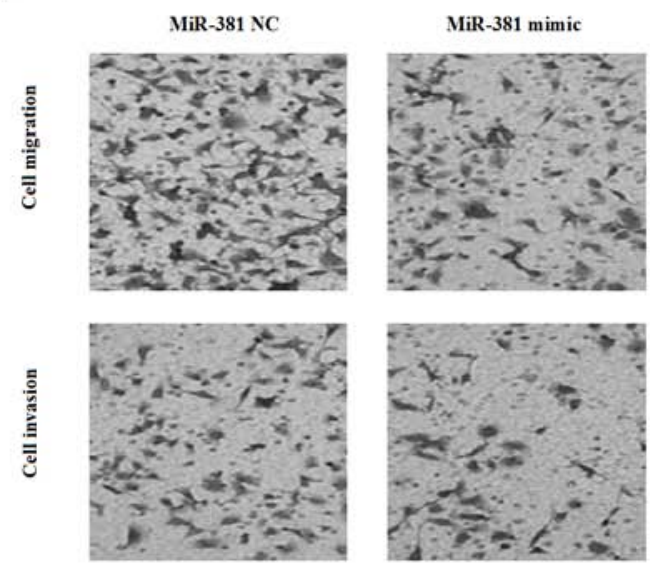

B

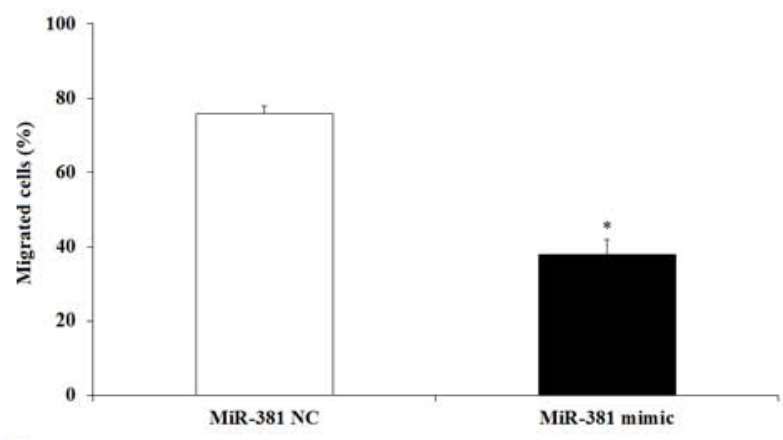

C

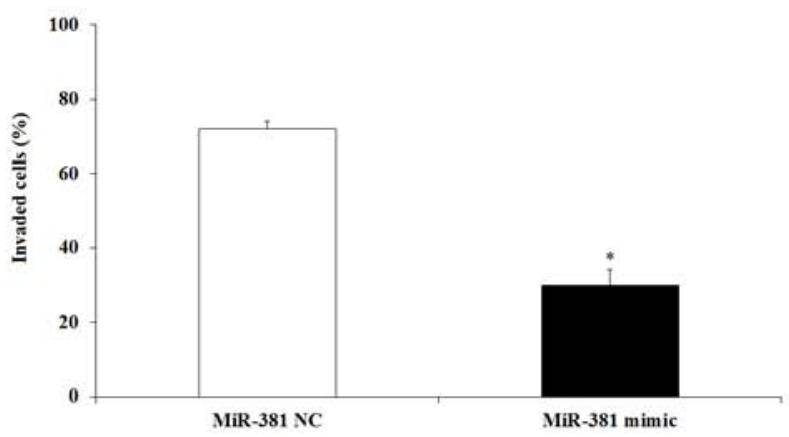

Figure 4. miR-381 inhibits gastric cancer SGC-7901 cell invasion and migration. (A) Representative images of migratory and invasive gastric cancer cells across a Transwell chamber (magnification, x200). (B) Quantification of migration of gastric cancer cells in the Transwell assay. (C) Quantification of invasion of gastric cancer cells in the Transwell assay. The data are presented as the mean \pm standard deviation. ${ }^{*} \mathrm{P}<0.05$. miR, microRNA; NC, negative control.

that expression of miR-381 may have enhanced GC cell apoptosis.

miR-381 decreases the expression of TWIST1 in GC cells. To investigate whether the effect of miR-381 on cell proliferation and apoptosis was caused by the regulation of TWIST1, western blotting and RT-qPCR were performed. The results indicated that the expression of TWIST1 was increased in GC cells compared with the immortalized human gastric epithelial GES cells (Fig. 6A and B). Transfection of miR-381 mimic significantly decreased the expression of TWIST1 in GC cells compared with the miR-381 NC group $(\mathrm{P}<0.05$; Fig. 6A and B). RT-qPCR results also indicated that transfection of TWIST1 siRNA decreased the expression of TWIST1 

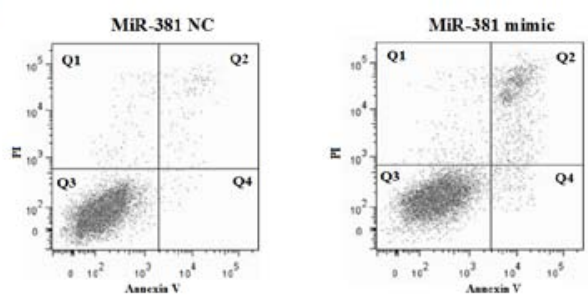

B

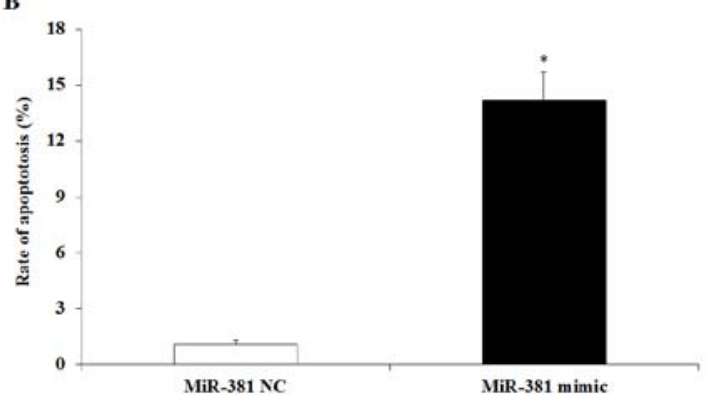

Figure 5. miR-381 induces gastric cancer SGC-7901 cell apoptosis. (A) Flow cytometry images representing cell apoptosis. (B) Quantification of cell apoptosis based on the flow cytometry results; the values in quadrants 2 and 4 were added together to determine rate of apoptosis $(\%)$. The data are presented as the mean \pm standard deviation. ${ }^{*} \mathrm{P}<0.05$ vs. miR-381 NC. $\mathrm{miR}$, microRNA; NC, negative control; PI, propidium iodide.

(Fig. 6C). As expected, TWIST1 knockout via co-transfection of miR-381 mimics and TWIST1-siRNA also inhibited GC cell growth (Fig. 6D). Therefore, these results demonstrated that upregulation of miR-381 may inhibit SGC-7901 GC cell growth by targeting TWIST1.

\section{Discussion}

GC is one of the most common types of cancer in the world (27). Approximately one-half of patients with GC survive $>5$ years (1). The high mortality rate of GC has been attributed to diagnosis at advanced stages and poor understanding of the pathology (28). Therefore, better assays for early-stage diagnosis and more efficient therapeutic strategies are required for GC prevention and treatment. Researchers have reported that miRs are associated with cancer progression, tumor invasion and metastasis $(29,30)$. Various studies have also reported that miR-381 is downregulated in a number of tumors, including cervical carcinoma, lung cancer, prostate cancer and GC (17-20). However, the biological role of miR-381 in GC development/progression remained poorly understood. The present study reported that the expression of miR-381 in GC cell lines was significantly decreased compared with GES cells. To selectively control the miR-381 expression in GC cells, miR-381 mimic transfection assays were performed. Consequently, miR-381 induction was observed to inhibit GC cell viability, invasion and migration. Moreover, overexpression of miR-381 significantly induced GC cell apoptosis, meaning that the observed GC cell decrease in viability may be attributed to an increase in apoptosis.

TWIST1, a basic helix-loop-helix transcription factor, is a known oncogene in humans (31). Previous studies indicated
A
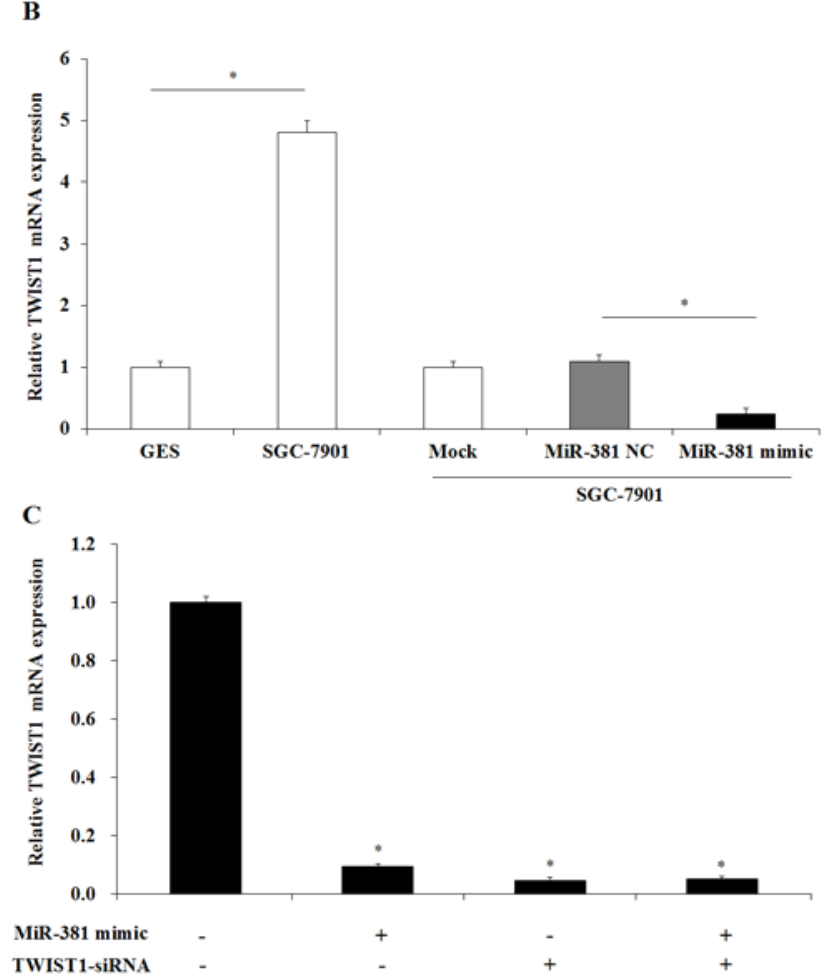

D

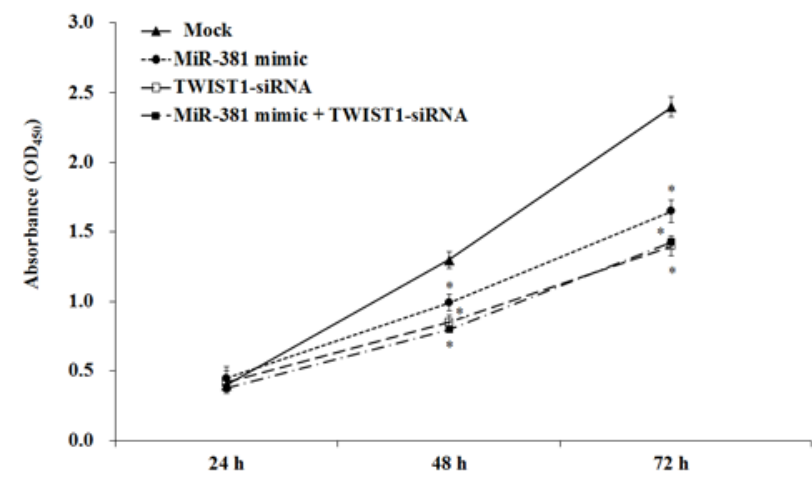

Figure 6. miR-381 regulates TWIST1 expression in SGC-7901 cells. (A) TWIST1 protein expression measured by western blotting. (B) Relative TWIST1 mRNA expression measured via RT-qPCR across the different cell lines/transfection groups. ${ }^{*} \mathrm{P}<0.05$. (C) TWIST1 mRNA expression measured via RT-qPCR for different miR-381 and TWIST1-siRNA treatment combinations. ${ }^{~} \mathrm{P}<0.05$ vs. control. (D) Cell viability according to the MTT assay. The data are represented as the mean \pm standard deviation. ${ }^{*} \mathrm{P}<0.05$ vs. respective Mock group. miR, microRNA; TWIST1, Twist-related protein 1; RT-qPCR, reverse transcription-quantitative polymerase chain reaction; siRNA, small interfering RNA; NC, negative control.

that TWIST1 is a target of a number of miRs, and may be involved in the proliferation, apoptosis and metastasis of various types of cancer. Zhu et al (26) reported that miR-186 regulates the cell cycle and induces cell apoptosis in ovarian cancer by targeting Twist1. Li and Wu (32) reported that miR-32 inhibits non-small-cell lung cancer cell proliferation, 
epithelial-mesenchymal transition and metastasis by targeting TWIST1. Bing et al (33) reported that miR-543 inhibits tumor cell proliferation, migration and invasion by targeting TWIST1. Additionally, Li et al (34) demonstrated that miR-720 inhibits breast cancer cell invasion and migration through TWIST1. TWIST1 has also been demonstrated to be expressed in human GC cell lines, including: MKN7, MKN45, NUGC4, HSC60, AGS and SGC-7901 $(35,36)$. In the present study, western blotting and RT-qPCR demonstrated that the expression of TWIST1 in SGC-7901 cells was increased compared with GES cells, while miR target prediction programs and luciferase assays indicated that TWIST1 is a target of miR-381. Moreover, the induction of miR-381 significantly decreased TWIST1 expression. Therefore miR-381 may regulate GC cell viability through TWIST1.

In conclusion, the present study demonstrated that miR-381 expression was decreased in GC cell lines compared with normal GES cells, and low expression of miR-381 was associated with the overexpression of TWIST1 in these cells. Moreover, forced expression of miR-381 suppressed GC cell viability and invasion, and induced cell apoptosis, possibly by directly targeting TWIST1. These results provide novel insights into the regulation of gastric tumorigenesis and progression by miRs. Upregulation of miR-381 may constitute a novel clinical treatment against GC in the future. However, to fully understand the effect of miR-381 in GC, further research, including the effect of miR-381 on cell cycle progression, is required.

\section{Acknowledgements}

Not applicable.

\section{Funding}

No funding was received.

\section{Availability of data and materials}

The datasets used and/or analyzed during the current study are available from the corresponding author on reasonable request.

\section{Authors' contributions}

YY and FZ designed the study. YY, XL and ZG performed the experiments, analyzed the data and prepared the manuscript. FZ reviewed the manuscript. All authors read and approved the final manuscript.

\section{Ethics approval and consent to participate}

Not applicable.

\section{Patient consent for publication}

Not applicable.

\section{Competing interests}

The authors declare that they have no competing interests.

\section{References}

1. Siegel RL, Miller KD and Jemal A: Cancer statistics, 2017. CA Cancer J Clin 67: 7-30, 2017.

2. Karpińska-Kaczmarczyk K, Lewandowska M, Białek A, Ławniczak M and Urasińska E: Gastric hyperplastic polyps coexisting with early gastric cancers, adenoma and neuroendocrine cell hyperplasia. Pol J Pathol 67: 33-38, 2016.

3. Ushijima $\mathrm{T}$ and Sasako M: Focus on gastric cancer. Cancer Cell 5: 121-125, 2004.

4. Smith MG, Hold GL, Tahara E and El-Omar EM: Cellular and molecular aspects of gastric cancer. World J Gastroenterol 12: 2979-2990, 2006.

5. Cunningham D, Allum WH, Stenning SP, Thompson JN, Van de Velde CJ, Nicolson M, Scarffe JH, Lofts FJ, Falk SJ, Iveson TJ, et al: Perioperative chemotherapy versus surgery alone for resectable gastroesophageal cancer. N Engl J Med 355: 11-20, 2006.

6. Vilaseca Cabo A, Musquera Felip M, Ribal Caparros MJ and Alcaraz Asensio A: Metastasis of gastric carcinoma simulating a urothelial tumor. Case report and review of the literature. Arch Esp Urol 66: 885-889, 2013 (In Spanish).

7. Compare D, Rocco A and Nardone G: Risk factors in gastric cancer. Eur Rev Med Pharmacol Sci 14: 302-308, 2010.

8. Huang H, Han Y, Zhang C, Wu J, Feng J, Qu L and Shou C: HNRNPC as a candidate biomarker for chemoresistance in gastric cancer. Tumour Biol 37: 3527-3534, 2016.

9. Li Y, Gong J, Zhang Q, Lu Z, Gao J, Li Y, Cao Y and Shen L: Dynamic monitoring of circulating tumour cells to evaluate therapeutic efficacy in advanced gastric cancer. Br J Cancer 114: $138-145,2016$.

10. Oue N, Aung PP, Mitani Y, Kuniyasu H, Nakayama H and Yasui W: Genes involved in invasion and metastasis of gastric cancer identified by array-based hybridization and serial analysis of gene expression. Oncology 69 (Suppl 1): S17-S22, 2005.

11. Iorio MV and Croce CM: MicroRNAs in cancer: Small molecules with a huge impact. J Clin Oncol 27: 5848-5856, 2009.

12. Glud M, Rossing M, Hother C, Holst L, Hastrup N, Nielsen FC, Gniadecki R and Drzewiecki KT: Downregulation of miR-125b in metastatic cutaneous malignant melanoma. Melanoma Res 20: 479-484, 2010.

13. Ueda T, Volinia S, Okumura H, Shimizu M, Taccioli C, Rossi S, Alder H, Liu CG, Oue N, Yasui W, et al: Relation between microRNA expression and progression and prognosis of gastric cancer: A microRNA expression analysis. Lancet Oncol 11: 136-146, 2010.

14. Croce C: Introduction to the role of microRNAs in cancer diagnosis, prognosis, and treatment. Cancer J 18: 213-214, 2012.

15. Holley CL and Topkara VK: An introduction to small non-coding RNAs: miRNA and snoRNA. Cardiovasc Drugs Ther 25: 151-159, 2011.

16. Iorio MV and Croce CM: microRNA involvement in human cancer. Carcinogenesis 33: 1126-1133, 2012.

17. Chen B, Duan L, Yin G, Tan J and Jiang X: miR-381, a novel intrinsic WEE1 inhibitor, sensitizes renal cancer cells to 5-FU by up-regulation of $\mathrm{Cdc} 2$ activities in 786-O. J Chemother 25: 229-238, 2013

18. Tang H, Wang Z, Liu Q, Liu X, Wu M and Li G: Disturbing miR-182 and -381 inhibits BRD7 transcription and glioma growth by directly targeting LRRC4. PLoS One 9: e84146, 2014.

19. Rothschild SI, Tschan MP, Jaggi R, Fey MF, Gugger M and Gautschi O: MicroRNA-381 represses ID1 and is deregulated in lung adenocarcinoma. J Thorac Oncol 7: 1069-1077, 2012.

20. Skalsky RL and Cullen BR: Reduced expression of brain-enriched microRNAs in glioblastomas permits targeted regulation of a cell death gene. PLoS One 6: e24248, 2011.

21. Martinez I, Gardiner AS, Board KF, Monzon FA, Edwards RP and Khan SA: Human papillomavirus type 16 reduces the expression of microRNA-381 in cervical carcinoma cells. Oncogene 27: 2575-2582, 2008.

22. Liao C, Wang J, Chen W, He D and Wang H: miR-381 regulates pituitary adenoma cell growth and migration by targeting TWIST1. Int J Clin Exp Pathol 10: 242-249, 2017.

23. Livak KJ and Schmittgen TD: Analysis of relative gene expression data using real-time quantitative PCR and the 2(-Delta Delta C(T)) method. Methods 25: 402-408, 2001.

24. Sung CO, Lee KW, Han S and Kim SH: Twist1 is up-regulated in gastric cancer-associated fibroblasts with poor clinical outcomes. Am J Pathol 179: 1827-1838, 2011. 
25. Qian J, Luo Y, Gu X, Zhan W and Wang X: Twistl promotes gastric cancer cell proliferation through up-regulation of FoxM1. PLoS One 8: e77625, 2013.

26. Zhu X, Shen H, Yin X, Long L, Xie C, Liu Y, Hui L, Lin X, Fang Y, Cao Y, et al: miR-186 regulation of Twist1 and ovarian can-cer sensitivity to cisplatin. Oncogene 35: 323-332, 2016.

27. Yoshikawa T, Aoyama T, Tanabe K, Nishikawa K, Ito Y, Hayashi T, Cho H, Miyashita Y, Tsuburaya A and Sakamoto J: Feasibility and safety of transhiatal approach and D2 total gastrectomy after neoadjuvant chemotherapy for adenocarcinoma of the Esophago-gastric junction: A subset analysis of the COMPASS trial. Dig Surg 33: 424-430, 2016.

28. Burkitt MD, Varro A and Pritchard DM: Importance of gastrin in the pathogenesis and treatment of gastric tumors. World J Gastroenterol 15: 1-16, 2009.

29. Nielsen CB, Shomron N, Sandberg R, Hornstein E, Kitzman J and Burge CB: Determinants of targeting by endogenous and exogenous microRNAs and siRNAs. RNA 13: 1894-1910, 2007.

30. Jazdzewski K, Boguslawska J, Jendrzejewski J, Liyanarachchi S, Pachucki J, Wardyn KA, Nauman A and de la Chapelle A: Thyroid hormone receptor beta (THRB) is a major target gene for microRNAs deregulated in papillary thyroid carcinoma (PTC). J Clin Endocrinol Metab 96: E546-E553, 2011.
31. Bourgeois P, Stoetzel C, Bolcato-Bellemin AL, Mattei MG and Perrin-Schmitt F: The human H-twist gene is located at 7p21 and encodes a B-HLH protein that is $96 \%$ similar to its murine M-twist counterpart. Mamm Genome 7: 915-917, 1996.

32. Li L and Wu D: miR-32 inhibits proliferation, epithelial-mesenchymal transition, and metastasis by targeting TWIST1 in non-small-cell lung cancer cells. Onco Targets Ther 9: 1489-1498, 2016.

33. Bing L, Hong C, Li-Xin S and Wei G: MicroRNA-543 suppresses endometrial cancer oncogenicity via targeting FAK and TWIST1 expression. Arch Gynecol Obstet 290: 533-541, 2014.

34. Li LZ, Zhang CZ, Liu LL, Yi C, Lu SX, Zhou X, Zhang ZJ, Peng YH, Yang YZ and Yun JP: miR-720 inhibits tumor invasion and migration in breast cancer by targeting TWIST1. Carcinogenesis 35: 469-478, 2014.

35. Sakamoto A, Akiyama Y, Shimada S, Zhu WG, Yuasa Y and Tanaka S: DNA methylation in the Exon 1 region and complex regulation of Twist 1 expression in gastric cancer cells. PLoS One 10: e0145630, 2015.

36. Yuan W, Li T, Mo X, Wang X, Liu B, Wang W, Su Y, Xu L and Han W: Knockdown of CMTM3 promotes metastasis of gastric cancer via the STAT3/Twist1/EMT signaling pathway. Oncotarget 7: 29507-29519, 2016. 